\title{
A Toxicological Aspect on Pepper Spray: Mini Review
}

\author{
Ezgi Öztas* and Mehtap Kara* \\ Faculty of Pharmacy, Department of Pharmaceutical Toxicology, Turkey
}

Received: 制: October 05, 2018; Published: 制: November 01, 2018

*Corresponding author: Ezgi Öztas, Mehtap Kara, Faculty of Pharmacy, Department of Pharmaceutical Toxicology, Turkey

\begin{abstract}
Tear gases as known "lacrimators" are are highly potent riot control agents which have strong irritant effects. Tear gases show their site-specific and time-dependent toxic effects via interaction with sensory neurons. These chemicals cause strong pain and irritation at the site of exposure area as mucous membranes, eyes or skin. Formulations of pepper spray contain different amounts of Oleoresin capsicum as major compound that is an oily resin derived from Capsicum annuum or Capsicum frutescenes. capsaicin and capsaicinoids are organic compounds of Oleoresin capsicum. These extracts primarily effects to ocular and skin and the other effects are on respiratory system, nervous system, mucous membranes and reproductive system. Pepper spray has been accepted by government and law enforcement agencies as less-than-lethal inflammatory agent. Pepper sprays active ingredients mostly associated with public health risk when they used. In this review we discussed chemical characteristics, systemic and local effects and the toxic effects on several systems of pepper spray and its main compound, capsaicin.
\end{abstract}

\section{Introduction}

For centuries, people have used pepper extracts and powdered fruits for various purposes including spice, weight loss, local anesthesia, anti-inflammatory and anti-microbial agent, primitive weaponry and recently production of self-defense and less thanlethal weaponry [1]. Samurai warriors have thrown powdered pepper with rice in special bags to enemies to cause temporary blindness and Chinese soldiers have used irritant pepper smoke to same purpose. In 1980s aerosol form of pepper was used by law enforcement agencies and public for self-defense [2]. Oleoresin capsicum or best known as pepper spray is the most widely used riot control agent in Europe, America and Turkey. It is easily accessible, cheap and effective harrasting agent that provide widespread usage $[3,4]$. Pepper spray causes an incapacitating inflammatory response associated with interaction with sensory nerves in mucous membranes and skin [5]. Pepper spray primarily affects eyes, however, also affects respiratory system and skin. Effects occur immediately after exposure and terminate in 30-45 minutes generally. Exposure volume, time, duration and environment may aggravate the effects. In the combat situation uncontrolled use of pepper spray has serious and prolonged consequences on vulnerable individuals such as kids, pregnant women, asthmatics and people have cardiovascular diseases. Besides of biological responses, throwing the canister causes traumatic injuries $[6,7]$.

\section{Pepper Spray: Oleoresin Capsicum}

Oleoresin capsicum (OC) is reddish brown oily extract derivate from Capsicum annuum or Capsicum frutescenes known as chili peppers. OC contains different amounts of capsaicinoids depend on type of plant, environment, climate, extraction conditions etc. [1,8]. The main compound that extracted from Oleoresin capsicum is capsaicin. Capsaicin is well absorbed from gastrointestinal system after oral administration and absorption rate shows regional differences through the gastrointestinal lumen. There is no sufficient data about absorption from respiratory system. However, after exposure via inhalation symptoms occur rapidly. Capsaicin is major metabolized in liver and also in kidney, lung, intestine secondary via oxidative and non-oxidative mechanisms. 16-hydrocapsaicin, 17-hydrocapsaicin and 16,17-dihydrocapsaicin are three major metabolites of capsaicin. Epoxide intermediates and highly reactive methyl radicals may produce by oxidative metabolisms. Capsaicin metabolized non-oxidative pathway through hydrolysis of acid amide bound. Metabolites of capsaicinoids are eliminated by urine via glucuronidation, further elimination via faeces may occur [911].

\section{Toxicity}

Acute toxic effects of pepper spray primary and rapidly occur on ocular system and respiratory system as local discomfort and pain. Ocular effects are mild to moderate such as burning pain, severe lacrimation, blepharospasm, blurred vision, ulceration and temporary or permanent blindness [12]. Repeated exposure to pepper spray may reduce corneal sensitivity [1]. Pepper spray also harm contact lenses so individuals who exposed pepper spray should take off contact lenses immediately [13]. After 
exposure to pepper spray via inhalation sneezing, prolong cough, pain, discomfortability of breathing, hipersalivation may occur. In addition, rarely, apnea and death associated with positional asphyxiation $[13,14]$. The relationship between pepper spray and asthma is not clear, yet. In spite of, many chemicals including pepper spray may trigger asthma attacks easily. When pepper spray contact with skin, itching, burning sensation, edema, erythema and rarely vesicule formation, second or third degree burns may occur [1]. In addition, contact dermatitis may occur or aggravate on allergic individuals. Pepper spray affects gastrointestinal system, nervous system, cardiovascular system and thermoregulatory system. Nausea, vomiting and diarrhea may occur in gastrointestinal system. Sensory and non-sensory neurons may affect by pepper spray and cause non-selective cellular responses such as inhibition of contraction of cardiac muscles. Furthermore, tachypnea, hypotension, bradycardia and at higher doses cardiac arrhythmia may occur [15].

\section{Conclusion}

It is believed that pepper spray is safe because it is easy attainable, cheap and natural source product. Symptoms occur in seconds after exposure and panic, disorientation, fear and aggressivness are secondary psychological effects. Furthermore, the solvents (trichloro ethylene, ethylene glycol etc.) and propellants that pepper spray contains, have various toxic effects. These may interact with Oleoresin capsicum and aggravate the toxic effects. Because of there is not sufficient data about total toxic effects of OC and its excipients, pepper spray is not classified as a safe product, yet. Nowadays, pepper spray becomes major incapacitating agent against protesters that don't matter who they are.

\section{References}

1. Pesonen $M$, Vähäkangas $K$, Halme $M$, Vanninen $P$, Seulanto $H$, et al. (2010) Capsaicinoids, chloropicrin and sulfur mustard: possibilities for exposure biomarkers. Front Pharmacol 1: 140.

2. Chan TC, Gary M Vike, Jack Clausen, Richard Clark, Paul Schmidt, et al. (2001) Pepper Spray's Effects on a Suspect's Ability to Breathe. National Institute of Justice Research in Brief.

\section{ISSN: 2574-1241}

DOI: $10.26717 / B J S T R .2018 .10 .001990$

Ezgi Öztas. Biomed J Sci \& Tech Res

This work is licensed under Creative Commons Attribution 4.0 License

Submission Link: https://biomedres.us/submit-manuscript.php
3. Haar RJ, Iacopino V, Ranadive N, Weiser SD, Dandu M (2017) Health impacts of chemical irritants used for crowd control: a systematic review of the injuries and deaths caused by tear gas and pepper spray. BMC Public Health 17(1): 831.

4. Arbak P, Başer I, Kumbasar ÖO, Ülger F, Kıllçaslan Z, et al. (2014). Long term effects of tear gases on respiratory system: analysis of 93 cases. ScientificWorldJournal 2014: 963638.

5. Garle MJ, Fry JR (2003) Sensory nerves, neurogenic inflammation and pain: missing components of alternative irritation strategies? A review and a potential strategy. Altern Lab Anim 31(3): 295-316.

6. Yeung MF, Tang WY (2015) Clinicopathological effects of pepper (oleoresin capsicum) spray. Hong Kong Med J 21(6): 542-552.

7. Çıl H, Atılgan ZA, Islamoglu Y, Tekbaș EÖ, Dostbil Z (2012) Is the pepper spray a triggering factor in myocardial infarction? A case report. Eur Rev Med Pharmacol Sci 16(Suppl 1): 73-74.

8. Reilly CA, Crouch DJ, Yost GS (2001) Quantitative analysis of capsaicinoids in fresh peppers, oleoresin capsicum and pepper spray products. J Forensic Sci 46(3): 502-509.

9. Al Othman ZA, Ahmed YBH, Habila MA, Ghafar AA (2011) Determination of Capsaicin and Dihydrocapsaicin in Capsicum Fruit Samples using High Performance Liquid Chromatography. Molecules 16(10): 8919-8929.

10. Fattori V, Hohmann MS, Rossaneis AC, Pinho Ribeiro FA, Verri WA (2016) Capsaicin: Current Understanding of Its Mechanisms and Therapy of Pain and Other Pre-Clinical and Clinical Uses. Molecules. 21(7).

11. Halme M, Pesonen M, Salo H, Söderström M, Pasanen M, et al. (2016) Comparison of in vitro metabolism and cytotoxicity of capsaicin and dihydrocapsaicin. J Chromatogr B Analyt Technol Biomed Life Sci 10091010: 17-24.

12. Broad stock M (2002) What is the safety of "pepper spray" use by law enforcement or mental health service staff? Nzhta Tech Brief Series 1(2).

13. Yeung MF, Tang WYM (2015) Clinicopathological effects of pepper (oleoresin capsicum) spray. Hong Kong Med J 21(6): 542-552.

14. Ashcroft C, Daniels DJ, Hart SV (2003) The effectiveness and safety of pepper spray, National Institute of Justice, Research for Practice.

15. Olajos EJ, Salem H (2001) Riot control agents: pharmacology, toxicology, biochemistry and chemistry. J Appl Toxicol.21(5): 355-391.

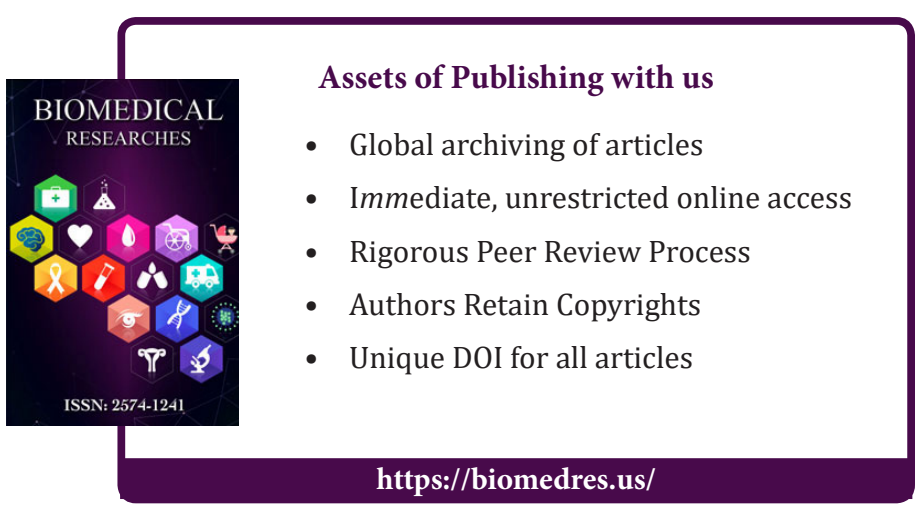

